\title{
Al-Ahkam: Kategori dan Implementasi
}

\author{
Dhaifina Fitriani \\ Universitas Islam Negeri Sunan Kalijaga Yogyakarta \\ dfdhaifinaf@gmail.com
}

\begin{abstract}
The law revealed by Allah Swt to humans aims for the benefit and safety of humans both in this world and in the hereafter. We will get this salvation if we obey Allah's laws consistently. The laws of Allah Swt that must be obeyed are in the nature of definite and undefined orders, orders to leave work with certainty and orders to leave work uncertainly such as whether to leave or not, and sometimes Allah SWT's law is optional. Sharia law 'is divided into taklifi law and wadh'i law. Taklifi law is a law that contains orders to be done or to be abandoned by mukallaf or which contains a choice between being done and left. There are five taklifi laws, namely obligatory, sunnah, permissible, makruh, and haram. While wadh'i law is a law that makes something as a cause for another, or a condition for something else or as a barrier for something else. Which includes the wadh' $i$ law there are seven, namely cause, condition, barrier (mani'), rukhsah, azimah, and valid (al-Shihhah) and null (al-Buthlan). The judge (shari') is Allah Swt. Therefore all Muslims agree that the judge (source of law) is Allah Swt, so the applicable law is the law of Allah Swt.
\end{abstract}

Key words: syara', taklifi, wadh'i

\begin{abstract}
Abstrak
Hukum yang diturunkan oleh Allah Swt kepada manusia bertujuan untuk kemaslahatan dan keselamatan manusia baik di dunia maupun di akhirat kelak. Keselamatan ini akan kita peroleh jika kita menaati hukum-hukum Allah Swt secara konsekuen. Hukum Allah Swt yang harus ditaati ada yang bersifat perintah tegas pasti dan perintah tidak tegas, perintah untuk meninggalkan pekerjaan secara pasti dan perintah untuk meninggalkan pekerjaan secara tidak pasti seperti boleh meninggalkan atau tidak, dan adakalanya hukum Allah Swt itu bersifat pilihan. Hukum syara' terbagi menjadi hukum taklifi dan hukum wadh'i. Hukum taklifi adalah hukum yang mengandung perintah untuk dikerjakan atau untuk ditinggalkan oleh mukallaf atau yang mengandung pilihan antara dikerjakan dan ditinggalkan. Yang termasuk hukum taklifi ada lima, yaitu wajib, sunnah, mubah, makruh, dan haram. Sedangkan hukum wadh'i adalah hukum yang menjadikan sesuatu itu sebagai sebab adanya yang lain, atau syarat bagi sesuatu yang lain atau sebagai penghalang bagi sesuatu yang lain. Yang termasuk hukum wadh'i ada tujuh, yaitu sebab, syarat, penghalang (mani'), rukhsah, 'azimah, serta sah (alShihhah) dan batal (al-Buthlan). Yang menjadi hakim (syari') adalah Allah Swt. Oleh karena itu semua umat Islam sepakat bahwa yang menjadi hakim (sumber hukum) adalah Allah Swt, maka hukum yang berlaku adalah hukum Allah Swt.

Kata kunci: syara', taklifi, wadh'i
\end{abstract}




\section{PENDAHULUAN}

Indikasi yang ditemukan dalam al-Qur'an dan Sunah merupakan sumber pokok dari syari'ah. Artinya, hukum figh digali dari al-Qur'an dan Sunah atas dasar prinsip dan metode yang secara kolektif dikenal sebagai usul al-figh (Kamali, 1996:1). Sebagaimana dikatakan oleh Imam Al-Ghazali bahwa mengetahui hukum syara' merupakan inti dari ilmu Figh dan Ushul Figh. Kedua ilmu ini berhubungan dengan perbuatan orang mukallaf meskipun dengan tinjauan yang berbeda. Ushul Figh meninjau hukum syara' dari segi metodologi dan sumber-sumbernya, sedangkan ilmu Figh meninjau dari segi hasil penggalian hukum syara', yakni ketetapan Allah Swt yang berhubungan dengan perbuatan orang-orang mukallaf baik berupa iqtidha'/tuntutan perintah atau larangan, takhyir/pilihan, maupun wadh'i/sebab akibat (Abu Zahrah, 1994:26).

Apabila diteliti semua perintah dan larangan Allah Swt dalam alQur'an, begitu pula perintah dan larangan Nabi Saw dalam sunah yang terumuskan dalam figh, akan terlihat semuanya mempunyai tujuan dan hikmah yang mendalam, yaitu sebagai rahmat bagi manusia, sebagaimana ditegaskan dalam beberapa ayat al-Qur'an, diantaranya dalam surat alAnbiya (21): 107 (Syarifuddin, 2009:219).

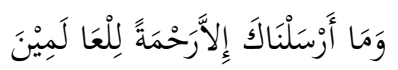

Artinya: "Tiadalah maksud kami mengutusmu kecuali menjadi rahmat bagi seisi alam."

Rahmat bagi seisi alam tersebut diartikan dengan kemaslahatan umat. Para ulama sepakat bahwa hukum syara' itu mengandung kemaslahatan untuk manusia (Syarifuddin, 2009:219).

\section{METODE PENELITIAN}

Tulisan ini bertujuan untuk menginformasikan pembaca tentang kategori dan implementasi hukum. Penulis menggunakan metode studi analisis (analysis studies) dengan pengumpulan data primer dan data sekunder dari library research (penelitian pustaka) serta menggunakan pendekatan normatif yuridis dalam menganalisa data.

\section{HASIL DISKUSI}

\section{Pengertian Hukum Syara'}

Menurut etimologi hukum berasal dari al-hukm (الحكم ) yang berarti mencegah, yaitu mencegah melakukan sesuatu yang berlawanan (Haroen, 1996:207). Hukm juga berarti qadha' ( القضاء ) yang berarti putusan, yaitu engkau telah memutuskan dan menyelesaikan kasus mereka. Hukum berarti (Sanusi dan Sohari, 2017:95):

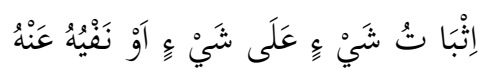


Artinya: "Menetapkan sesuatu atas sesuatu atau meniadakan sesuatu daripadanya."

Sedangkan menurut terminologi, hukum berarti (Sanusi dan Sohari, 2017:95):

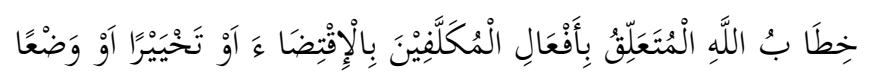

Artinya: "Tuntutan Allah Swt yang bersangkutan dengan perbuatan mukallaf (orang yang telah baligh dan berakal). Baik titah itu mengandung tuntutan, suruhan atau larangan, atau sematamata menerangkan kebolehan, atau menjadikan sesuatu itu sebab, atau syarat atau penghalang bagi sesuatu hukum."

Dapat disimpulkan bahwa hukum syara' adalah tuntutan Allah Swt yang mengatur amal perbuatan orang mukallaf baik berupa iqtidha (perintah, larangan, anjuran untuk melakukan atau anjuran untuk meninggalkan), takhyir (kebolehan bagi orang mukallaf untuk memilih antara melakukan dan tidak melakukan) atau wadh'i (ketentuan yang menetapkan sesuatu sebagai sebab, syarat dan mani'/penghalang (Hasbiyallah, 2013:29).

Seperti perintah untuk أَوْفُوْا بِالْعُعُوْدِ (tepatilah janji). Menurut ulama ushul figh, ayat ini berarti menghendaki keharusan memenuhi janji. Sedangkan menurut ulama figh merupakan konsekuensi yang dikehendaki oleh ayat tersebut berupa kewajiban untuk memenuhi janji. Perintah lainnya لَاتَفَرَبُوْ الزَّنَا (janganlah kamu semua mendekati perbuatan zina). Menurut ulama ushul figh ayat tersebut bermakna berupa larangan mendekati zina sedangkan menurut ulama figh adalah 'hukum haram' mendekati zina (Shidiq, 2011:124).

\section{Pembagian Hukum Syara'}

1. Hukum Taklifi

a. Pengertian Hukum Taklifi

Hukum taklifi adalah hukum yang menghendaki dilakukannya suatu perbuatan oleh mukallaf atau melarang mengerjakannya atau disuruh memilih antara melakukan atau meninggalkannya (Shidiq, 2011:124).

b. Pembagian dan Implementasi Hukum Taklifi (Hanafie, 1961:12)

1) Ijab (Wajib)

Wajib menurut syara' adalah مَا طَلَبَ عَلَى وَجْهِ اللُّزُوْمِ فِعْلُهُ artinya sesuatu yang diperintahkan Allah Swt agar dikerjakan secara pasti. Wajib merupakan ketentuan perintah yang harus dilakukan oleh mukallaf sesuai petunjuk yang telah ditentukan dengan konsekuensi akan mendatangkan pahala 
jika dilakukan dan akan mendatangkan dosa jika ditinggalkan (Shidiq, 2011:127).

Contoh tuntutan untuk dilaksanakan seperti shalat, puasa, membayar zakat, menunaikan haji bagi orang mampu dan berbakti kepada kedua orang tua (Shidiq, 2011:127).

Artinya: "Sembahlah Allah Swt." (Sanusi dan Sohari, 2017:96)

Tuntutan untuk mengerjakan ada pada firman Allah Swt dalam surat at-Taubah (9):103 (Hasbiyallah, 2013:30).

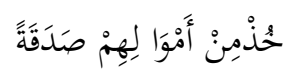

Artinya: "Ambillah sebagian harta mereka sebagai zakat..."

Pembagian hukum wajib dibagi menjadi empat, yaitu (Hasbiyallah, 2013:30):

a) Dilihat dari segi waktu pelaksanaan

Wajib muwaqqat, yaitu kewajiban yang waktu pelaksanaannya terikat oleh waktu, misalnya shalat lima waktu dan puasa di bulan Ramadhan.

Wajib muthlaq, yaitu kewajiban yang tidak terikat oleh waktu, misalnya mengqadha puasa.

b) Dilihat dari segi mukallaf sebagai pelaksana

Wajib 'ain, yaitu kewajiban yang diperintahkan Allah Swt untuk dikerjakan mukallaf secara individu. Misalnya shalat, zakat, dan haji.

Wajib kifayah, yaitu kewajiban yang diperintahkan Allah Swt yang dianggap cukup jika hanya dikerjakan oleh seorang atau sekelompok mukallaf. Misalnya shalat jenazah, membangun rumah sakit, dan menjawab salam.

c) Dilihat dari segi ukuran sesuatu yang diwajibkan

Wajib muhaddad (dibatasi ukurannya), yaitu kewajiban yang ukurannya sudah diketahui dengan jelas. Misalnya shalat dan zakat.

Wajib ghairu muhaddad (tidak dibatasi), yaitu kewajiban yang ukurannya tidak ditentukan oleh agama. Misalnya bersedekah, menolong orang yang dalam kesulitan, dan memberi nafkah istri.

d) Dilihat dari segi kesempatan bagi mukallaf untuk melakukannya 
Wajib muayyan (tertentu), yaitu kewajiban yang diwajibkan Allah Swt kepada mukallaf untuk melakukannya tanpa meninggalkannya. Misalnya shalat lima waktu, puasa, harga sesuatu yang dibeli. Kewajiban ini akan terus menjadi tanggungannya sampai ia melaksanakan.

Wajib mukhayyar (boleh memilih), yaitu kewajiban yang harus dilakukan mukallaf dengan memilih antara beberapa pilihan. Misalnya Allah Swt mewajibkan kepada orang yang melanggar sumpah untuk memberi makan orang miskin atau memberi pakaian atau memerdekakan budak. Maka seorang mukallaf wajib memilih di antara beberapa pilihan tersebut.

2) Mandub (Sanusi dan Sohari, 2017:97)

Mandub menurut syara' adalah perintah dari Allah Swt untuk dilakukan mukallaf secara tidak tegas. Dengan kata lain berupa perintah yang tidak sampai kepada derajat wajib (Shidiq, 2011:130), sehingga tidak mesti dikerjakan (Sanusi dan Sohari, 2017:97). Firman Allah Swt dalam surat alBaqarah (2):282 (Sanusi dan Sohari, 2017:97).

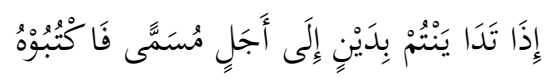

Artinya: "Apabila kamu utang dengan berjanji akan membayarnya pada ketika yang telah ditentukan, maka tulislah utang itu."

Perintah menulis atau membuat keterangan tertulis tidak bersifat wajib melainkan merupakan anjuran, sebab pada akhir ayat tersebut Allah Swt berfirman lagi dalam surat alBaqarah (2):283 (Sanusi dan Sohari, 2017:97).

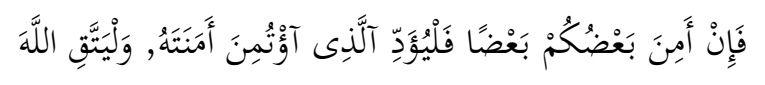

Artinya: "Akan tetapi jika sebagian kamu mempercayai sebagian yang lain, maka hendaklah yang dipercayai itu menunaikan amanatnya (utangnya) dan hendaklah ia bertakwa kepada Allah Swt."

Dengan demikian, konsekuensi dalam perintah ini jika dilakukan akan mendapat pahala dan tidak mendapat dosa jika ditinggalkan (Shidiq, 2011:127). Contoh dari perintah 
sunah seperti mencatat utang, shalat sunah, puasa sunah, dan mengucapkan salam.

Pembagian sunah dibagi menjadi tiga tingkatan, yaitu:

a. Sunah muakkadah (sunah yang dianjurkan) adalah perbuatan yang biasa dilakukan Rasulullah Saw dan jarang ditinggalkan (Hasbiyallah, 2013:32). Seperti adzan, shalat berjamaah, dan berkumur ketika berwudhu (Shidiq, 2011:131).

b. Sunah ghairu muakkadah (biasa) adalah perbuatan yang dilakukan Rasulullah Saw namun bukan menjadi kebiasaan (Hasbiyallah, 2013:32). Seperti shalat sunah sebelum shalat lima waktu dan berpuasa senin kamis setiap minggu (Shidiq, 2011:131).

c. Sunah zaidah (sunnah tambahan) yaitu perbuatan mengikuti segala perbuatan Rasul Saw berupa kebiasaan sehari-hari Rasul Saw sebagai manusia biasa (Hasbiyallah, 2013:32). Seperti cara makan dan minum Nabi Saw, memelihara jenggot, dan mencukur kumis (Shidiq, 2011:131).

3) Tahrim (Shidiq, 2011:132).

Haram adalah berupa tuntutan yang tegas dari Allah Swt untuk tidak dikerjakan secara pasti. Konsekuensi dari hukum haram ini adalah seseorang yang mengerjakannya akan mendapat dosa dan kehinaan sedangkan bagi yang meninggalkannya akan mendapat pahala dan kemuliaan. Contoh dari perintah yang haram untuk dilaksanakan seperti berzina, mencuri, membunuh tanpa hak, dan makan harta dengan dzalim (Shidiq, 2011:132), dan juga larangan yang sesuai firman Allah Swt dalam surat al-Isra (17):23 (Sanusi dan Sohari, 2017:97).

$$
\text { فَلاً تَقُقْ لَّهُمَا أُفْبِ وَلاَ تَنْهَرْ هُمَا }
$$

Artinya: "Janganlah kamu mengatakan kepada keduanya perkataan 'ah' dan janganlah kamu membentak mereka dan ucapkanlah kepada mereka perkataan yang mulia."

Pembagian hukum haram dibagi menjadi dua, yaitu (Shidiq, 2011:132):

a. Haram lidzatih, yaitu keharaman yang ditetapkan oleh syari' sejak semula karena esensinya mengandung mudharat bagi kehidupan manusia (Hasbiyallah, 2013:33) yakni agama, jiwa, akal, harta dan keturunan 
(Shidiq, 2011:132), seperti berzina, makan bangkai dan minum arak.

b. Haram lighairih, yaitu keharaman yang ditetapkan oleh syari' yang disebabkan oleh sesuatu yang lain atau hukum yang semulanya bukan haram maka akan menjadi haram dikarenakan adanya sesuatu hal yang datang dari luar, seperti shalat dengan pakaian hasil mencuri, jual beli yang di dalamnya ada unsur tipuan, dan lainnya (Shidiq, 2011:132).

4) Karahah (Makruh)

Makruh adalah perintah yang mengandung larangan agar seseorang tidak mengerjakannya, tetapi perintah ini sifatnya tidak pasti atau tidak tegas (Shidiq, 2011:133), sebagaimana firman Allah Swt dalam surat al-Jumuah (62):6 (Sanusi dan Sohari, 2017:98).

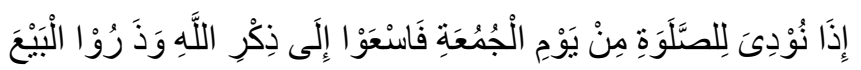

Artinya: "Apabila diseru untuk menunaikan shalat Jum'at, maka bersegeralah kamu kepada mengingat Allah Swt dan tinggalkanlah jual beli."

Dalam ayat diatas, "tinggalkanlah jual beli" berarti jangan kamu berjualan, hanya saja karena larangan jual beli ini sebagai sebab di luar dari pekerjaan itu maka larangan tersebut tidak bersifat mengharamkan melainkan hanya memakruhkan (Sanusi dan Sohari, 2017:98).

Ulama Hanafiyah membagi makruh menjadi dua, yaitu (Hasbiyallah, 2013:34):

a. Makruh tahrim, yaitu sesuatu yang dilarang oleh syariat tetapi dalil yang melarang bersifat zhanni seperti larangan meminang wanita yang sedang dalam pinangan orang lain. Menurut mayoritas ulama makruh tahrim ini sama dengan hukum haram.

b. Makruh tanzih, yaitu sesuatu yang dianjurkan oleh syariat untuk meninggalkannya seperti memakan daging kuda dan meminum susunya pada waktu perang.

5) Ibahah (Mubah)

Mubah adalah sesuatu yang diperbolehkan Allah Swt untuk memilih antara mengerjakan atau meninggalkan. Dengan kata lain, Allah Swt tidak menyuruh dan tidak melarang, namun konsekuensi dari hukum mubah ini adalah jika 
dikerjakan akan berpahala dan jika ditinggalkan tidak berdosa. Contohnya berburu setelah melakukan haji, bertebaran setelah shalat Jumat, mengqashar shalat ketika bepergian jauh, dan mencatat transaksi utang piutang (Hasbiyallah, 2013:34).

\section{Hukum Wadh'i}

\section{a. Pengertian Hukum Wadh'i}

Hukum wadh'i adalah hukum yang menjadikan sesuatu sebagai suatu sebab adanya yang lain, atau syarat bagi sesuatu yang lain atau sebagai penghalang bagi sesuatu yang lain. Menurut Abdul Wahab Khalaf dan Wahbah Zuhaili, pembagian hukum wadh'i bukan hanya terbatas kepada tiga bagian tersebut saja (sebab, syarat dan penghalang), namun termasuk juga sahih, buthlan, 'azimah dan rukhsah. Mereka mendefinisikan hukum wadh'i sebagai hukum yang menghendaki adanya sesuatu itu sebagai sebab bagi sesuatu yang lain atau sebagai syarat atau sebagai penghalang atau sebagai sesuatu yang memperkenankan keringanan (rukhsah) atau sebagai pengganti hukum ketetapan pertama ('azimah) atau sebagai yang sahih dan tidak sahih (Hasbiyallah, 2013:34).

b. Pembagian dan Implementasi Hukum Wadh'i

1) Sebab

Sebab adalah sesuatu yang bisa menyampaikan seseorang kepada sesuatu yang lain (Hasbiyallah, 2013:36), yang menjadi akibatnya. Para ulama mendefinisikan sebagai "sesuatu yang jelas dan dapat diukur, yang dijadikan oleh pembuat hukum sebagai tanda adanya hukum, lazim dengan adanya tanda itu ada hukum dan dengan tidak adanya tidak ada hukum" (Shidiq, 2011:134-135).

Contoh masuknya bulan Ramadhan menjadi pertanda adanya kewajiban berpuasa di bulan Ramadhan. Masuknya bulan Ramadhan disebut sebab, sedangkan adanya kewajiban berpuasa disebut akibat hukum. Masuknya bulan Ramadhan adalah sesuatu yang jelas dan dapat diukur (Shidiq, 2011:134-135). Sesuai dengan firman Allah Swt dalam surat al-Baqarah (2):185:

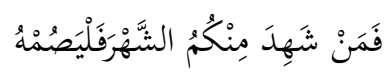

Artinya: "Barangsiapa di antara kamu hadir (di negeri tempat tinggalnya) di bulan itu, maka hendaklah ia berpuasa pada bulan itu."

Dilihat dari sumbernya, Muhammad Abu Zuhrah membagi sebab menjadi dua (Shidiq, 2011:134-135): 
a. Sebab yang timbul bukan dari perbuatan mukallaf. Sebab ini merupakan sesuatu yang dijadikan Allah sebagai pertanda adanya hukum. Contohnya masuk waktu shalat merupakan sebab diwajibkan shalat, dharurat merupakan sebab bolehnya memakan bangkai dan minum arak, kematian merupakan sebab dari pembagian warisan.

b. Sebab yang ditimbulkan dari perbuatan mukallaf. Seperti pembunuhan yang dilakukan mukallaf dengan sengaja merupakan sebab adanya hukum qishas dan perjalanan jauh merupakan sebab adanya rukhsah bolehnya tidak berpuasa.

Dilihat dari logis tidaknya, Abdul Karim Zaidan membagi sebab menjadi dua (Shidiq, 2011:134-136):

a. Sebab illat (sebab yang logis), yaitu antara sebab dan musabab memiliki hubungan yang logis (diterima akal). Seperti memabukkan disebut sebagai sebab sekaligus illat bagi keharaman minum khamar dan perjalanan adalah sebab sekaligus illat bagi bolehnya berbuka puasa di siang hari bulan Ramadhan.

b. Sebab bukan illat (sebab yang tidak logis), yaitu antara sebab dan musabab tidak memiliki hubungan yang logis (tidak dapat ditelusuri oleh akal). Seperi terbenamnya matahari menjadi sebab bagi wajibnya melaksanakan shalat Magrib dan terbit fajar menjadi sebab bagi wajibnya melaksanakan shalat Subuh.

2) Syarat

Menurut para ulama, syarat adalah sesuatu yang menghendaki adanya sesuatu yang lain sebagai tanda (Hasbiyallah, 2013:38). Ada dan tidak adanya hukum tergantung kepada ada dan tidak adanya sesuatu (syarat tersebut).

Contohnya hubungan perkawinan suami istri adalah menjadi syarat untuk menjatuhkan talak. Jika tidak ada perkawinan maka tidak adanya talak, tetapi bukan berarti dipahami bahwa dengan adanya hubungan suami istri akan menetapkan adanya talak. Wudhu adalah syarat sahnya shalat, tanpa wudhu maka tidak sah mendirikan shalat, tetapi bukan berarti adanya wudhu menetapkan adanya shalat (Shidiq, 2011:137). 
Ulama ushul figh membagi syarat menjadi dua, yaitu (Shidiq, 2011:137-138):

a. Syarat syar'i, yaitu syarat yang secara langsung didatangkan oleh syariat. Contohnya membunuh adalah sebab diwajibkannya qishas, dengan syarat dilakukan secara sengaja.

b. Syarat ja'ly, yaitu syarat yang keberadaanya diciptakan oleh mukallaf. Contohnya dalam masalah talak. Seorang suami yang berkata kepada istrinya "Jika kamu ke rumah si fulan tanpa izin dariku maka talakmu jatuh satu", atau orang yang berpuasa nazar "Saya akan berpuasa tiga hari jika saya lulus dalam ujian skripsi".

3) Penghalang (Mani')

Secara bahasa mani' artinya penghalang. Dalam istilah ushul fiqh mani' berarti sesuatu yang dengan wujudnya dapat meniadakan hukum atau membatalkannya. Contohnya seorang anak berhak mendapatkan warisan dari ayahnya yang sudah meninggal. Namun karena beberapa hal bisa menjadi penghalang bagi si anak untuk mendapatkan warisan seperti murtad dan kematian ayahnya disebabkan karena dibunuh olehnya (Shidiq, 2011:139).

Ulama ushul figh membagi mani' menjadi dua, yaitu (Shidiq, 2011:139-140).

a. Mani' hukum, yaitu mani' yang keberadaannya diciptakan oleh syara' sebagai penghalang munculnya hukum. Seperti keadaan haid yang menjadi penghalang bagi keharusan seorang wanita untuk melaksanakan shalat.

b. Mani' sebab, yaitu mani' yang ditetapkan oleh syara' sebagai penghalang bagi berfungsinya suatu sebab sehingga sebab itu tidak lagi memiliki akibat hukum. Seperti dalam hal zakat. Jika jumlah utang mengakibatkan berkurangnya harta mencapai nisab, maka hal tersebut menjadi penghalang bagi seseorang untuk membayar zakat.

4) 'Azimah

'Azimah adalah hukum yang berlaku secara umum yang telah disyariatkan Allah Swt sejak semula tidak ada kekhususan lantaran suatu kondisi. "Berlaku secara umum" bermakna berlaku untuk semua mukallaf dan "disyariatkan oleh Allah Swt sejak semula" bermakna bahwa pada awalnya pembuat hukum bermaksud untuk menetapkan hukum taklif kepada hambanya. Contohnya shalat lima 
waktu yang diwajibkan kepada semua mukallaf dalam semua situasi dan kondisi, begitu juga kewajiban zakat, puasa, dan lainnya. Semua kewajiban ini berlaku untuk semua mukallaf dan tidak ada hukum yang mendahului hukum wajib tersebut (Shidiq, 2011:140).

5) Rukhsah

Rukhsah adalah keringanan hukum yang disyariatkan Allah Swt kepada mukallaf dalam kondisi tertentu yang menghendaki keringanan (Wahab Khalaf, 1992:204). Rukhsah dibagi menjadi tiga, yaitu (Shidiq, 2011:141):

a. Menggugurkan kewajiban ketika mendapatkan uzur (kesulitan untuk menunaikan). Contoh seperti orang yang sakit atau dalam perjalanan di siang hari pada bulan Ramadhan maka dibolehkan berbuka. Begitu juga bagi musafir boleh mengqashar shalat. Orang yang dalam keadaan dharurat boleh makan bangkai atau minum khamar.

b. Pengecualian. Contohnya jual beli salam yang sah dilakukan karena telah menjadi 'urf. Orang yang dipaksa (kalau tidak melakukan akan dibunuh) mengucapkan kata-kata kafir.

c. Penghapusan (nasakh), yaitu hukum Allah Swt yang berlaku bagi umat sebelum kita tetapi tidak berlaku lagi bagi kita. Contoh memotong sebagian pakaian yang terkena najis, membayar seperempat harta dalam zakat, membunuh diri dalam rangka bertaubat dan tidak boleh melakukan shalat selain di masjid.

6) Sah (Al-Shihhah) dan Batal (Al-Buthlan)

Setiap perbuatan mukallaf dapat dihukum sah atau batal. Perbuatan yang dilakukan oleh mukallaf bisa dikatakan sah apabila telah memenuhi dengan sempurna rukun dan syarat serta terlepas dari penghalangnya. Sebaliknya, jika perbuatan itu tidak sesuai dengan tuntutan syariat dan tidak sempurna rukun dan syaratnya makan perbuatan tersebut batal oleh syariat. Contohnya dalam jual beli yang dilakukan sesuai dengan hukum syara' dan telah terpenuhi semua rukun dan syaratnya maka jual beli tersebut sah. Namun jika dalam akad jual beli mengandung unsur gharar dan lainnya maka jual beli tersebut gugur dan batal (Shidiq, 2011:141142). 


\section{PENUTUP}

Secara bahasa hukum syara' berarti mencegah dan memutuskan. Menurut istilah hukum syara' adalah kitab Allah Swt yang bersangkutan dengan perbuatan mukallaf (orang yang telah baligh dan berakal). Baik titah itu mengandung tuntutan, suruhan atau larangan, atau semata-mata menerangkan kebolehan, atau menjadikan sesuatu itu sebab, atau syarat atau penghalang bagi sesuatu hukum. Adapun tujuan umum adanya hukum Islam adalah untuk meningkatkan kemaslahatan dan menghilangkan kesempitan serta menolak bahaya.

Hukum syara' terbagi menjadi dua yaitu hukum taklifi dan hukum wadh'i. Hukum taklifi adalah hukum yang menghendaki dilakukannya suatu perbuatan oleh mukallaf atau melarang mengerjakannya atau suruhan untuk memilih antara melakukan atau meninggalkannya. Hukum taklifi ada lima yaitu wajib, sunah, haram, makruh dan mubah. Sedangkan hukum wadh'i adalah hukum yang menjadikan sesuatu itu sebagai sebab adanya yang lain atau syarat bagi sesuatu yang lain atau sebagai penghalang bagi sesuatu yang lain. Hukum wadh'i ada tujuh yaitu sebab, syarat, penghalang, 'azimah, rukhsah, sah dan batal.

\section{DAFTAR PUSTAKA}

Bakry, Nazar. (1994). Figh dan Ushul Fiqh. Jakarta: Raja Grafindo.

Djazuli, HA. (2010). Kaidah-Kaidah Fikih. Jakarta: Prenada Media Group.

Hanafie, A. (1961). Ushul Figh. Jakarta: Wijaya.

Haroen, Nasrun. (1996). Ushul Fiqh. Jakarta: Logos Publishing House.

Hasbiyallah. (2013). Fiqh dan Ushul Figh. Bandung: Remaja Rosdakarya.

Kamali, Muhammad Hashim. Prinsip dan Teori-Teori Hukum Islam (Usul AlFiqh).

Noorhaidi, penerjemah. (1996) Yogyakarta: Pustaka Pelajar. Terjemahan dari: Principles of Islamic Jurisprudence (The Islamic Texts Society).

Khalaf, Abdul Wahab. (1992) Ilmu Ushulul Figh. Bandung: Gema Risalah Press.

Sanusi, Ahmad dan Sohari. (2017). Ushul Fiqh. Jakarta: Rajawali Pers.

Syarifuddin, Amir. (2009). Ushul Figh. Jakarta: Kencana.

Shidiq, Sapiudin. (2011). Ushul Fiqh. Jakarta: Kencana.

Zahrah, Muhammad Abu. Ushul Fiqih. Saefullah Ma'shum, Slamet Basyir, Mujib Rahmat, dkk, penerjemah. Jakarta: Pustaka Firdaus. Terjemahan dari: Ushul al-Figh, 19. 